\title{
Chapter 9 \\ Design and Performance of a Pilot Scale High-Gradient Magnetic Filter Using a Mandhala Magnet and Its Application for Soy-Whey Protein Purification
}

\author{
Katharina Menzel, Victor Alvan Amasifuen and Hermann Nirschl
}

\begin{abstract}
The scalability of economic high-gradient magnetic separation (HGMS) technology is essential in order to demonstrate the feasibility of the concept. One of the means is the application of a permanent magnet with a hollow cylindrical volume made from identical magnetic blocks (e.g., Mandhala), another is the development of a High-Gradient Magnetic Filter (HGMF) with a new backwashing concept. The Mandhala (Magnetic Arrangement for Novel Discrete Halbach Layout) magnet produces a dipolar transversal magnetic field in the center of the bore and its usable volume is easily adaptable to the separation device's extensions. The chapter presents the pilot scale design of the Mandhala magnet and the HGMF as well as experimental performance tests using a water-magnetic beads model system. Subsequently, experiments using soy-whey as a real feedstock demonstrate the purification of the protein Bowman-Birk inhibitor (BBI), an agent against cancer and multiples sclerosis.
\end{abstract}

\subsection{Introduction}

Conventional High-Gradient Magnetic Separation (HGMS) is a batchwise process with alternate magnetic particle separation and backwashing: Smart magnetic supports with selective functionalization enable an efficient adsorption of target products from the crude stock. Followed by magnetic separation and washing, the product is isolated by elution, then the beads are recyclable.

K. Menzel $(\bowtie) \cdot$ V. Alvan Amasifuen

Karlsruhe Institute of Technology, Institute of Mechanical Process Engineering

and Mechanics, Karlsruhe, Germany

e-mail: katharina.menzel@ kit.edu

H. Nirschl

Institute of Mechanical Process Engineering and Mechanics, Karlsruhe Institute of Technology, 76131 Karlsruhe, Germany

e-mail: hermann.nirschl@kit.edu 
Recently, several new magnetically separation devices have been developed and tested at lab scale, e.g., (Becker et al. 2009; Kaeppler et al. 2009; Lindner et al. 2010). To demonstrate the feasibility of the concept for industrial applications, it is essential to develop large-scale HGMS apparatuses. Two major obstacles so far were the lack of an up-scalable and economic magnetic field generating device as well as a separation cell optimized regarding efficient particle detachment from the separation matrix. The application of cylindrical permanent magnets made from identical magnet blocks (Menzel et al. 2013, 2014) and the new concept of High-Gradient Magnetic Filter (HGMF) design help to overcome these barriers.

This chapter demonstrates the application of a Mandhala magnet (Magnetic Arrangement for Novel Discrete Halbach Layout) (Raich and Blümler 2004) for HGMS. The magnet generates a dipolar transversal field, which implies an axial and/ or transversal wire to field to flow configuration (Gerber and Birss 1983). The openable hinged concept adapted from Windt et al. (2011) is convenient for easy placement and accessibility of the separation device. The arrangement is compact, light, and therefore easy transportable in contrast to an electromagnets or a c-shaped magnet. The present work adjusts the magnetic flux density calculation concept by Menzel et al. (2013) based on the dipole approach by Soltner and Blümler (2010). The comparison between the adapted analytic approach and field measurement proves if the modifications remedy the gap between them, which was present in (Menzel et al. 2013).

The filter cell is equipped with rotatable wire matrices, intermediate pitched blade impellers and a spraying nozzle array below the top of the filter cell. The work presents performance tests of the pilot scale separation apparatus carried out with a water-magnetic beads model system. The first criteria is the separation efficiency, the second is the backwashing behavior. Subsequently, a real feedstock is used to demonstrate the separation of Bowman-Birk inhibitor (BBI) from soy-whey using magnetic ion-exchange particles. The process is assessed regarding protein content, sucrose content, purity and purification factor as well as target protein concentration factor.

\subsection{Design of the Mandhala Magnet}

The work on the Mandhala magnet for NMR (nuclear magnetic resonance) applications by Raich and Blümler (2004), Soltner and Blümler (2010) and Windt et al. (2011) gave the major inspiration for its application as a magnetic field generating device in HGMS. The transversal dipolar Mandhala magnet, shown in Fig. 9.1a, consists of $n$ magnets, ${ }^{1}$ whose magnetization direction differs by $720 \%$ between neighboring magnets. The field in the center of such a Mandhala ring is directed in $z$-direction (transversal), perpendicular to the fluid flow direction along the $x$-axis. Figure 9.1b shows schematically the magnetic flux density distribution, simulated using the finite element method (FEM) (www.comsol.com), generated by a Mandhala magnet.

\footnotetext{
${ }^{1}$ Where $n$ is the number of identical permanent magnet blocks within one Mandhala ring and $n=8+k \cdot 4\left(k \in \mathbb{N}^{0}\right)$, zero is included: $\mathbb{N}^{0}=0,1,2, \ldots$
} 
(a)

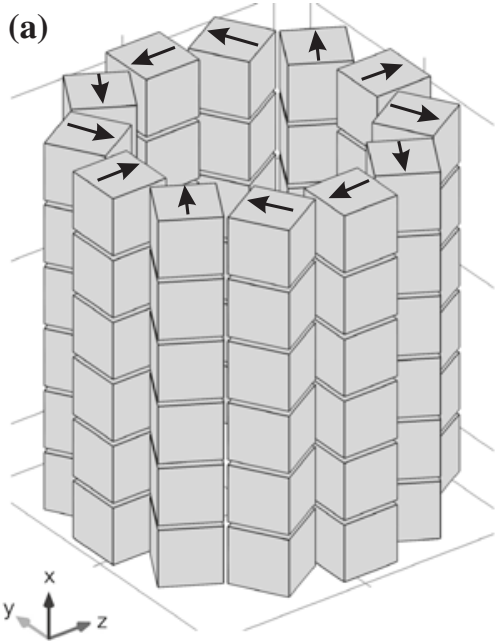

(b)

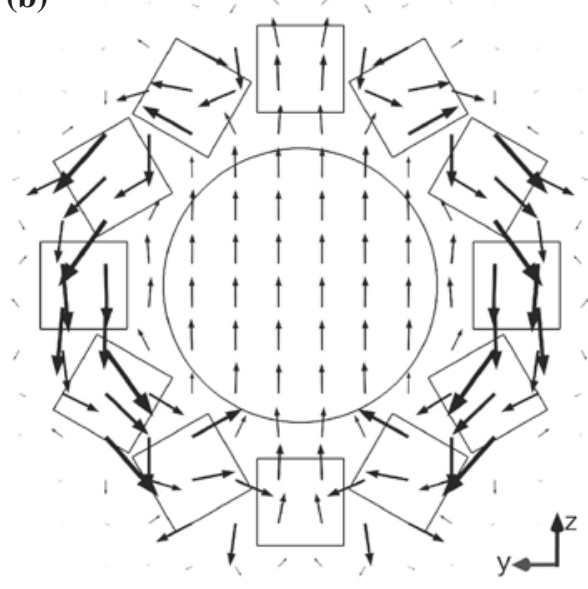

Fig. 9.1 Mandhala magnet design and magnetic field with definition of the coordinate system, whose origin is located in the center of the hollow inner volume. a Mandhala magnet with equidistant stacking of six rings consisting of twelve magnets each. b FEM vector field of the magnetic flux density in and around the Mandhala magnet (www.comsol.com) (top view y-z plane). Arrow size is proportional to the magnetic flux density B

Menzel et al. (2013) presented an analytic concept that allows to calculate the magnetic flux density in the center of the hollow inner volume of a Mandhala magnet. Nevertheless, the comparison between measurement and analytic field calculation emerged an offset. There are two reasons for the difference. First is that Raich and Blümler (2004) investigated Mandhalas with $n=8+k \cdot 8$ magnets per ring and calculated the auxiliary function $\Xi(n)$. The function describes the ratio $a / r$ between the side length of the magnet $a$ and magnet's center radius $r$ as $a / r=2 \cdot \Xi(n)$. Later Soltner and Blümler (2010) found that the restriction to $n=8+k \cdot 8$ is not necessary and it is sufficient to define $n=8+k \cdot 4$. They showed how to stack multiple Mandhala rings, but did not redefine the auxiliary function $\Xi(n)$. For $n=12+k \cdot 8$ the original auxiliary function $\Xi(n)$ causes an overlapping of magnets and is therefore not applicable in this case. Second is that former works did not consider that neighboring cubes in real arrangements must not touch each other due to space requirements of the structural material. The use of a reduced side length corrects this disagreement. The next subsections present a summary of the calculation concept and introduce the two adjustments, which close the gap between measurement and analytic solution.

\subsubsection{Dipole Approximation for a Mandhala Magnet}

The dipole approximation is based on the replacement of cube magnets by point source dipoles of the same magnetic moment, which are located in the center of the substituted geometry. It is valid if the distance between the magnet surface and 
the observation point $z$ in relation to the magnet side length $a$ is sufficiently large $(z / a>1)$. The concept permits to develop a formula for the magnetic flux density along the bore axis $x$ for a series of stacked rings (Menzel et al. 2013). It is

$$
B_{z, m}(x)=3 / \pi \cdot n \cdot B_{r} \cdot \Xi(n)^{3} \cdot f(x),
$$

with the number of magnets within the ring $n=8+k \cdot 4$, the remanence of the magnet $B_{r}$ and the auxiliary function $\Xi(n)$ defined through $a=2 r \cdot \Xi(n)$. The dimensionless superposition function $f$ includes the contribution of an even number of multiple rings $m$ to the total magnetic flux density:

$$
f(x)=\sum_{i=1}^{m / 2}\left\{\left[1+\left(\left(x-s_{i}\right) / r\right)^{2}\right]^{-5 / 2}+\left[1+\left(\left(x+s_{i}\right) / r\right)^{2}\right]^{-5 / 2}\right\} .
$$

The choice of the normalized $x$-coordinates of the dipole rings, $s_{i} / r$, strongly influences the magnetic flux density, its distribution, and therefore its homogeneity. The use of an equidistant stacked rings ensures a high magnet packing density and easy construction. The normalized displacement in $x$-direction, $s_{i} / r$, for an equidistant array is deduced from geometry. It is

$$
s_{i} / r=0.5 \gamma+\Xi+(i-1)(\gamma+2 \Xi)
$$

for $i=1,2,3, \ldots, m / 2$ with relative distance $\gamma=b / r$ and the absolute distance $b$ between the Mandhala rings. Each magnet ring generates a magnetic flux density along the center axis $x$, which describes a Voigt peak function (similar to a Gauss function). The stacking of the rings corresponds to the superposition of the curves. To ensure curve continuity, $\gamma$ has to be chosen in the range of $0 \leq \gamma \leq 0.1$.

In real arrangements, structural material is necessary to fit the magnets into their positions. Hence, the neighboring magnets edges might not touch each other, which was an assumption in former works. Therefore, a reduced magnet's side length

$$
a^{*}=v a
$$

with the reduction ratio $v$ corrects this disagreement.

As stated before the auxiliary function $\Xi$ for $n=8+k \cdot 8$ magnets per ring was developed by Raich and Blümler (2004). To extent the scope to $n=8+k \cdot 4$, the geometric layout of Mandhala rings with $n=12+k \cdot 8$ have to be regarded. Figure 9.2a depicts the schematic representation of the magnet coordinates for this case. The angle between two magnet centers $\alpha$ is $\frac{2 \pi}{n}$. The two magnets which surround the angles $45^{\circ}+l \cdot 90^{\circ}(l=0,1,2,3)$, respectively, have maximum extension along the circumference of the circle with radius $r$. Their edge distance is shortest for $a^{*}$ or even vanishes if the maximum side length $a$ is considered.

Figure $9.2 \mathrm{~b}$ depicts the two adhering magnets in more detail. The side length $a$, the reduced side length $a^{*}$ and subsequently the auxiliary function $\Xi$ are retrievable with the following geometric correlations: First, the length $\overline{\mathrm{AB}}$ within the triangle $\triangle$ Origin $\mathrm{AB}$ results in

$$
\overline{\mathrm{AB}}=r \sin \alpha / 2
$$


(a)
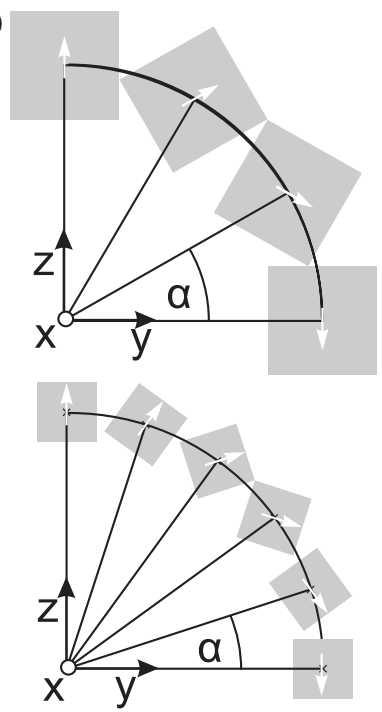

(b)

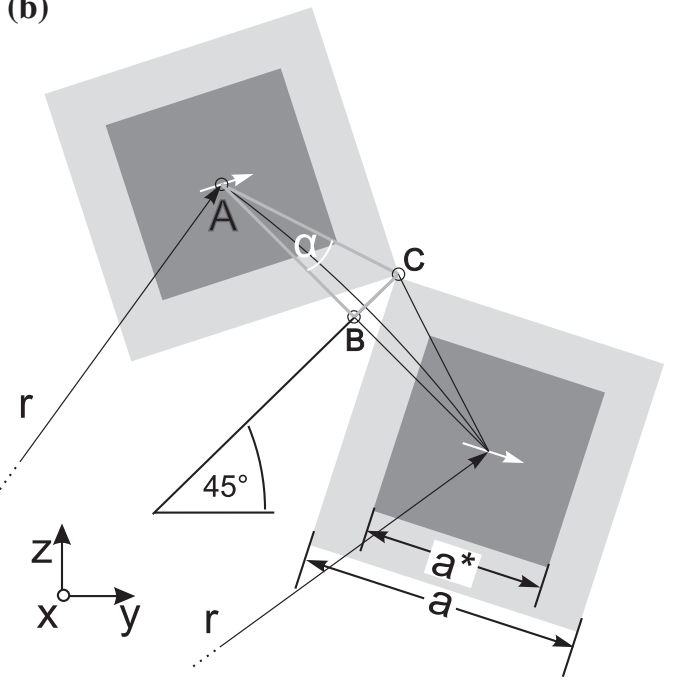

Fig. 9.2 Schematic representation of the magnet coordinates in Mandhala rings with $n=12+k \cdot 8$ magnets per ring. Arrows indicate the magnetization direction. Definition of the coordinate system and the symbols used. a Quarter of Mandhala rings Quarter of Mandhala rings with $n=12$ and 20 magnets. b Detail cross-section

Second, the distance between point $\mathrm{A}$ and $\mathrm{B}$ within the connection $\triangle \mathrm{ABC}$ equals

$$
\overline{\mathrm{AB}}=\overline{\mathrm{AC}} \cos \alpha .
$$

Third, it applies that

$$
\overline{\mathrm{AC}}=\frac{a}{\sqrt{2}}=\frac{a^{*}}{v \cdot \sqrt{2}} .
$$

The insertion of Eqs. 9.5 and 9.7 into Eq. 9.6 and resolving for $a^{*}$ gives

$$
a^{*}=2 r \cdot \frac{v \sqrt{2} \sin (\pi / n)}{2-4 \sin ^{2}(\pi / n)} .
$$

Finally, the auxiliary function is

$$
\Xi(n, v)=\left\{\begin{array}{l}
\frac{v \cdot\left\{\cos \left(\frac{2 \pi}{n}\right)-\sin \left(\frac{2 \pi}{n}\right)-\sqrt{2} \sin \left(\frac{\pi}{4}-\frac{4 \pi}{n}\right)\right\}}{2 \cos \left(\frac{\pi}{4}-\frac{4 \pi}{n}\right)+\sqrt{2}} \\
\text { if } n=8+k \cdot 8 \text { for } k \in \mathbb{N}^{0} \text { or } \\
\frac{\nu \sqrt{2} \sin (\pi / n)}{2-4 \sin ^{2}(\pi / n)} \\
\text { if } n=12+k \cdot 8 \text { for } k \in \mathbb{N}^{0}
\end{array}\right.
$$

\subsubsection{Comparison of Dipole Model Results and Measurement}

The built hinged Mandhala magnet (see Fig. 9.4a) can be opened easily. It consists of $n=12$ magnets/ring with side length $a^{*}=35 \mathrm{~mm}$ and $m=6$ magnet rings. 


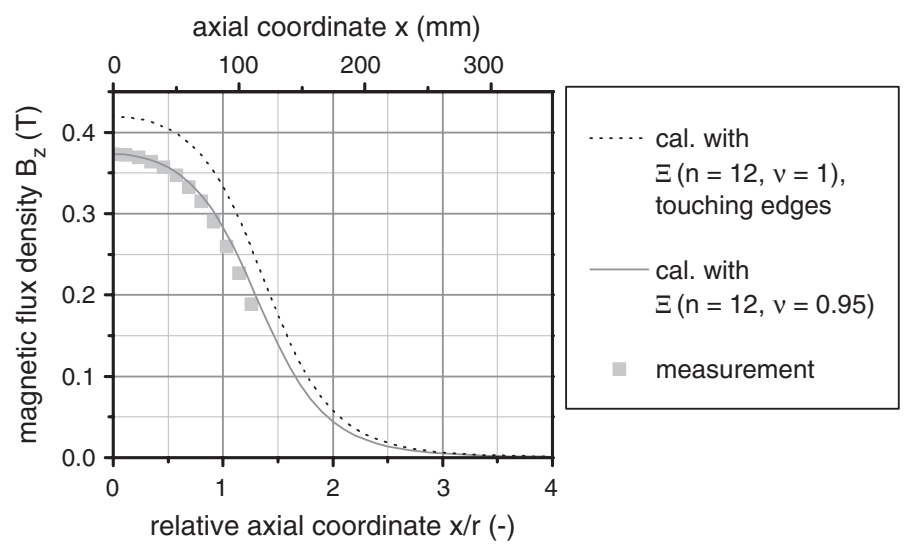

Fig. 9.3 Magnetic flux density $B_{z}$ as a function of the relative axial coordinate $x / r$ or axial coordinate $x$ of a Mandhala magnet with $n=12$ magnets/ring and $m=6$ magnet rings that are equidistantly stacked with $\gamma=0.034$. Comparison between measurement and the calculation using $\Xi(n, v)$ of Eq. 9.9

The design and construction is reported in more detail by Menzel et al. (2013). The structural material has $2.08 \mathrm{~mm}$ minimum wall thickness and the magnet's center radius $r$ is $87.208 \mathrm{~mm}$, which gives a maximum magnet's side length $a=2 r \cdot \Xi(n=12, v=1)$ of $36.89 \mathrm{~mm}$. Therefore, the reduction factor $v=\mathrm{a}^{*} / a$ is 0.95 .

It is possible to calculate the magnetic flux density $B_{z}$ along the bore axis $x$ using Eqs. 9.1, 9.2, 9.3 and 9.9 and compare it with flux density measurement. The magnetic field is scanned with a Hall-sensor, type FH 51 of Magnet-Physik Dr. Steingroever GmbH. Figure 9.3 depicts the measurement and the calculation of $B_{z}$ using $v=1$ and $v=0.95$ as a function of the (relative) axial coordinate $x$ or $x / r$. The measured magnetic flux density is $0.37 \mathrm{~T}$ in the center and does not decrease below $0.27 \mathrm{~T}$ within the filter length of $160 \mathrm{~mm}$. The calculation using $v=0.95$ shows good agreement with the measurement. The effect of the reduced side length $a^{*}=v a$ and the new auxiliary function $\Xi$ is to lower the magnetic flux density by $17.6 \%$ in the center of the magnet. With these two modifications, the gap between measurement data and the calculation, which was present in (Menzel et al. 2013), reconciles.

\subsection{Design of the Filter Cell and Its Operation}

The filter cell, shown in Fig. 9.4, is placed inside the hollow volume of the dipolar Mandhala magnet. The filter cell's inner diameter is $100 \mathrm{~mm}$ and its height is $160 \mathrm{~mm}$. It is made of glass to enable the observation of the backwashing process. A capillary (Fig. 9.4b, 2) equipped with three flat jet inserts is installed at the top of 
Fig. 9.4 Dipolar transversal Mandhala magnet and separation cell equipped with stirrer motors (1) at the top and bottom. The motors rotate the two star-shaped matrix elements $(3 a, 3 b)$ and two impeller elements (4) with four inclined blades independently from each other. The wash liquid is introduced pulsewise by a capillary equipped with three flat jet inserts (2). a Opened Mandhala magnet and elevated filter cell. b Interior view of the filter cell (a)

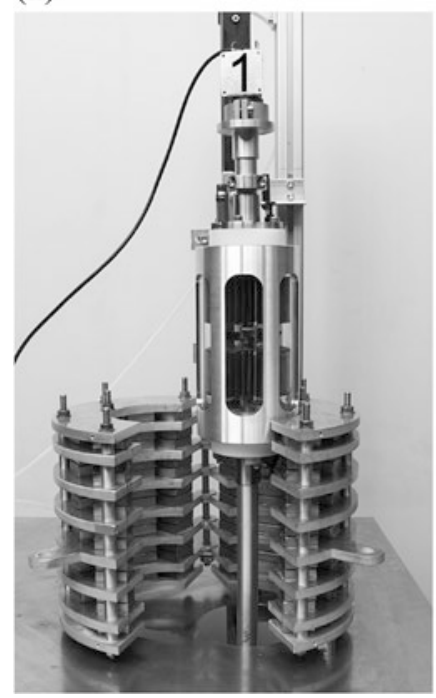

(b)

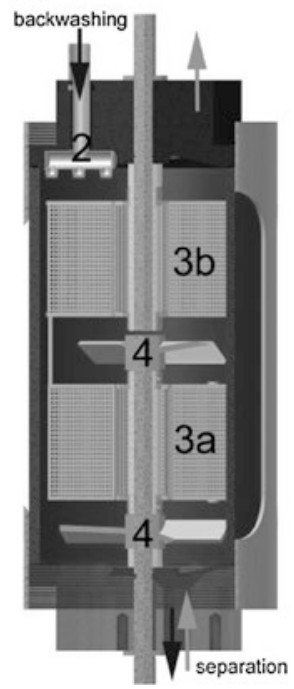

the filter cell in order to inject the backwashing liquid. The two lateral nozzles possess a spraying angle of $30^{\circ}$ with a volume flow of $11 / \mathrm{min}$ at 2 bar liquid pressure (flat jet insert from Lechler GmbH AV 634.40217). The center nozzle has a spraying angle of $120^{\circ}$ and a volume flow of $0.63 \mathrm{l} / \mathrm{min}$ at 2 bar liquid pressure (flat jet insert AV 634.367 17). The matrices (Fig. 9.4b, 3a, 3b) have a height of $50 \mathrm{~mm}$ and are rotatable by a motor (Fig. 9.4a, 1). They are made of magnetizable stainless steel (X6 Cr 17 (1.4016), AISI 430) wire meshes that are starlike arranged. The coarse matrix mesh (Fig. 9.4b, 3a) has a wire diameter of $0.4 \mathrm{~mm}$ and a mesh width of $1 \mathrm{~mm}$. The fine matrix (Fig. 9.4b, 3b) is made of wire mesh with a wire diameter of $0.25 \mathrm{~mm}$ and a mesh width of $0.375 \mathrm{~mm}$. The detachment of the particles is assisted by two impeller elements (Fig. 9.4b, 4) with four inclined blades, which are revolving independently from the matrices. They are angled by $45^{\circ}$ to the left (regarding to the impeller axis) and are considered as mixed-flow turbines because they exhibit velocity components in both axial and radial direction (Paul 2004).

A pneumatic lifting device vertically moves the filter cell into and out off the magnetic field. Naturally, during filtration the cell is placed inside the hollow volume of the Mandhala magnet. For backwashing, it is removed from the magnetic field. Although the forces are small enough to manually split, open, and close the magnet a convenient pneumatic piston, which controls the separation of the two halves, is installed.

The pilot setup, shown in Fig. 9.5, consists of a stirred feed vessel (Fig. 9.5, 1), a peristaltic pump (Fig. 9.5, 2), the developed HGMS apparatus (Fig. 9.5, 3) and a collecting vessel for the filtrate (Fig. 9.5, 4). The stirred feed suspension is fed into the separation cell at the bottom and leaves it as filtrate at the top. The filter cell collects particles until the matrix is saturated. After the separation process, the filter cell is removed from the magnet and regenerated by backwashing. A pressurized 
Fig. 9.5 Pilot setup with stirred feed vessel (1), a peristaltic pump (2), the developed HGMS apparatus (3) and a collecting vessel for the filtrate (4). Backwashing is performed pulse by pulse with a pressurized tank (5) and a programmable $2 / 2$ way valve (6)

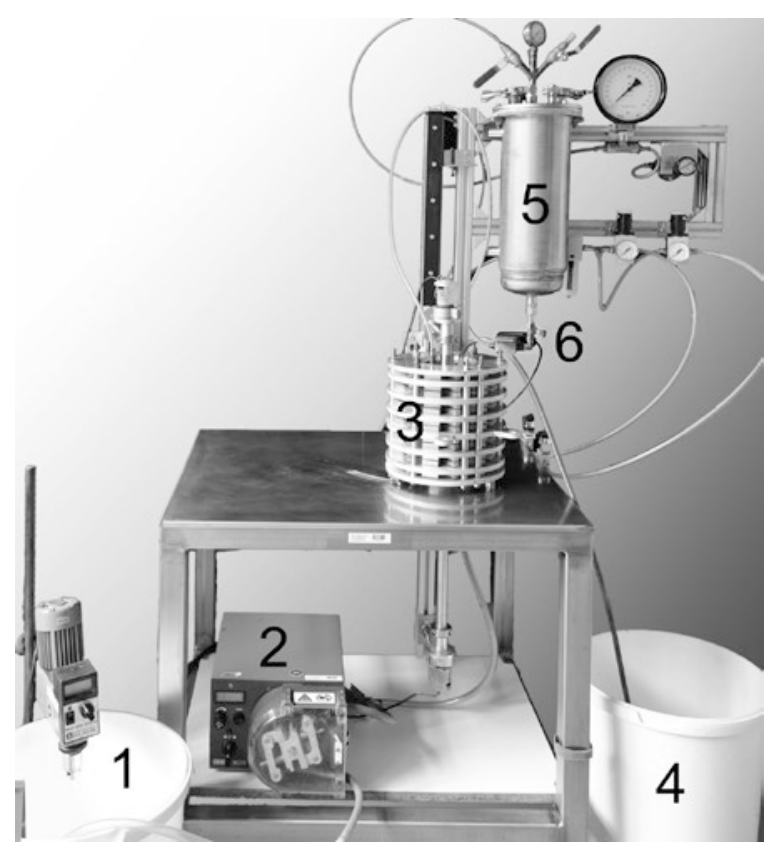

tank (Fig. 9.5, 5) contains the washing liquid. A 2/2-way solenoid valve (Bürkert $\mathrm{GmbH}$, Type 0330 with timer unit 1078) pulses the flow with an adjustable repetition frequency $(P R F)$ and time $t_{\mathrm{s}}$. The repetition frequency is the reciprocal of the time between the pulses $T$.

\subsection{System Performance}

The soy-whey protein purification involves magnetic separation and resuspension of the magnetic particles. Therefore, it is important to characterize the system's performance by looking at both unit operations. Lab scale experiments showed that the BBI-antibody functionalized MagPrep beads are best suited to purify BBI, but their utilization is too expensive. Hence, the application of magnetic anion exchange carriers MagPrep® TMAP (Trimethylammoniumpropyl-functionalized magnetic silica particles) and Orica Watercare MIEX® DOC resin ('Magnetic Ion EXchange' with anion exchange group that binds 'Dissolved Organic Carbon') are substitute particles that performed well enough to justify further experiments at larger scale. However, only Orica particles were available in sufficient quantity for pilot experiments on BBI purification. As the Orica particles are large and easily separable, the separation of smaller plain MagPrep® Silica beads (courtesy of Merck Millipore KGaA, Darmstadt) is more challenging. Therefore, the plain MagPrep® Silica beads are suitable to accomplish the system performance tests. 
The next two sections present the evaluation of particle loss as a function of the inflow velocity and the backwashing behavior of the developed HGMS cell with the Mandhala magnet.

\subsubsection{Particle Loss}

A low particle loss, which translates to a high separation efficiency of magnetic beads, is important in order to reduce costs for subsequent particle addition and to increases productivity. Therefore, it is essential to determine the maximum inflow velocity with economically justifiable particle loss.

\subsubsection{Method}

The experiments are realized at volume flows of 20, 50, 70, 100, 150, and $200 \mathrm{l} / \mathrm{h}$, which is equivalent to inflow velocities between 0.71 and $7.07 \mathrm{~mm} / \mathrm{s}$. The MagPrep® Silica beads are suspended in deionized water, which exhibits pH 7.0 adjusted with $0.05 \mathrm{M} \mathrm{Na}_{2} \mathrm{HPO}_{4}$ and $0.05 \mathrm{M} \mathrm{NaH}_{2} \mathrm{PO}_{4}$. Before it is adjusted to the final concentration, a rotor-stator disperser T 25 Ultra-Turrax ${ }^{\circledR}$ disagglomerates the particles within the suspension for $15 \mathrm{~min}$ at $8,000 \mathrm{rpm}$. The final feed suspension (10 1 total volume) exhibits a concentration of $18 \mathrm{~g} / \mathrm{l}$ and is poured into a stirred feed vessel (Fig. 9.5, 1).

The analysis of feed and filtrate takes place at equidistant time intervals. The relative particle loss $c_{f} / c_{0}$ relates the mass concentration of the filtrate $c_{f}$ to the concentration of the feed $c_{0}$. High concentrated feed and filtrate suspensions were measured gravimetrically using weighed empty glasses for sampling. The mass concentration

$$
c=\frac{m_{p}}{m_{\mathrm{susp}}}
$$

is given by dividing the solid mass $m_{p}$ by the total suspension mass $m_{\text {susp. }}$ The two masses are both determined by weighing the glass after and before separating and evaporating the liquid.

The concentration of dilute filtrate samples is determinable offline by a $90^{\circ}$ scattering light absorption turbidimeter (Hach 2100P). It measures between 0 and 800 nephelometric turbidity unit (NTU). In this range, the scattering intensity is straight proportional to the concentration. However, the slope of the linear correlation is a function of the size and absorption properties of the particles. Therefore, a calibration of turbidity as a function of the suspension concentration is necessary (not shown). Foster et al. (1992), Lewis (1996) showed that the calibration slope of smaller particles is steeper than that of larger particles. It is a matter of fact that bigger particles are separated more easily than smaller ones. Hence, assuming that the particle size distribution does not change within the magnetic separation process, which corresponds to a constant grade efficiency, overestimates the particle loss. 


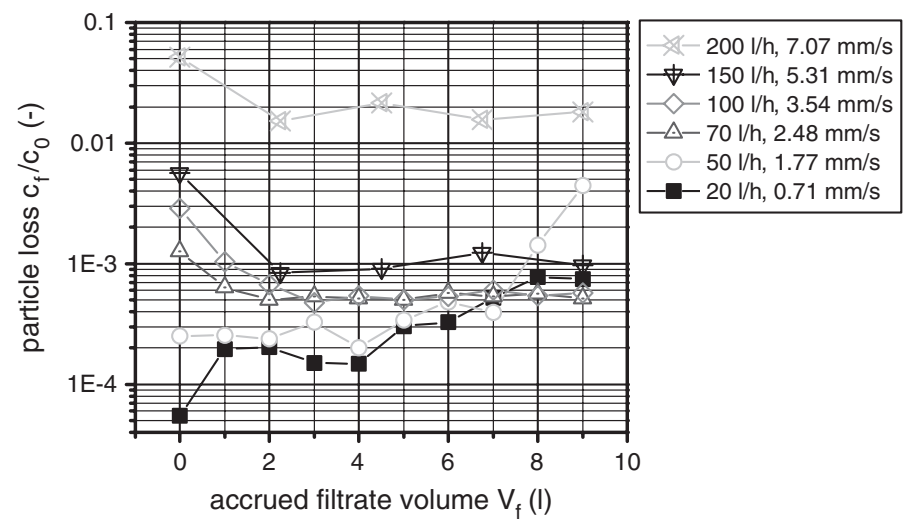

Fig. 9.6 Particle loss of MagPrep ${ }^{\circledR}$ Silica increases with growing volume flow or flow velocity, respectively. The feed concentration is approximately $18 \mathrm{~g} / \mathrm{l}$

\subsubsection{Results}

In Fig. 9.6 the relative particle loss $c_{f} / c_{0}$ is shown as a function of the accrued filtrate volume $V_{f}$ at six different volume flows or flow velocities. As expected, the curves shift to higher product loss with growing volume flow. Between $20 \mathrm{l} / \mathrm{h}$ and $100 \mathrm{l} / \mathrm{h}$ the particle loss averages to below 0.001 , which is equivalent to a separation efficiency above $99.9 \%$. At $200 \mathrm{l} / \mathrm{h}$ the particle loss ascends to 0.02 and the separation decreases to $98 \%$. The graph depicts that no drastic particle loss increase (break-through) took place. The filter capacity amounts therefore to at least $160 \mathrm{~g}$ MagPrep® Silica. If the apparatus is applied in production process, an online monitoring system, e.g., turbidity measurement, at the exit of the filter chamber is advisable to prevent particle loss and to determine when backwashing has to be initiated.

\subsubsection{Backwashing Behavior}

The backwashing behavior of the developed HGMS cell with Mandhala magnet is the second criterion for performance evaluation. To save process time and costs, the required cleanliness of the separation cell is reached with as little washing liquid as possible. The experiments investigate the influence of rotational speed and the sense of rotation of the wire matrices and impellers. The residue of particles in the separation chamber is examined as a function of the necessary volume of wash liquid.

The observation of the flow pattern inside the filter chamber aims to ascertain how the different parameters influence the backwashing results and to identify those for optimized performance. The analysis reveals the effects of the rotational direction of impellers and matrices. They can either rotate separately or simultaneously and in clockwise or counter clockwise direction. 


\subsubsection{Theory}

The characterization of the backwashing process follows a concept adapted from the scientific work on filter cake washing by Ruslim et al. (2009). The wash diagram displays the relative residue $r^{*}$ of magnetic particles in the HGMS cell as a function of the wash ratio $W$. It enables the dimensionless characterization of the backwashing and therefore the prediction of a large-scale process.

The wash ratio is

$$
W=\sum_{i=1}^{j} \frac{V_{\mathrm{ws}, i}}{V_{\mathrm{cell}}}
$$

with the volume of liquid that leaves the cell in each washing step $i$

$$
V_{\mathrm{ws}, i}=\frac{m_{\mathrm{susp}, \mathrm{ws}, i}}{\rho_{\mathrm{wl}}} \cdot\left(1-c_{\mathrm{ws}, i}\right)
$$

and the cell volume $V_{\text {cell }}=1.261$. The density of the clean wash liquid $\rho_{\mathrm{wl}}$ is assumed to be $1 \mathrm{~g} / \mathrm{cm}^{3}$. The mass of the flushed suspension $m_{\mathrm{susp}, \mathrm{ws}, i}$ and its mass concentration $c_{\mathrm{ws}, i}$ were determined for every washing step $i=1,2, \ldots j$ by gravimetric analysis, described in Sect. 9.4.1.1.

Furthermore, the relative residue $r^{*}$ is

$$
r^{*}=1-\frac{\sum_{i=1}^{j} m_{\mathrm{ws}, i}}{m_{\mathrm{sep}}} .
$$

The particle mass $m_{\mathrm{ws}, i}$, which is flushed out of the cell, isrepetition frequency

$$
m_{\mathrm{ws}, i}=c_{\mathrm{ws}, i} \cdot m_{\mathrm{susp}, \mathrm{ws}, i}
$$

with particle mass concentration $c_{\mathrm{ws}, i}$ and the suspension mass $m_{\mathrm{susp}, \mathrm{ws}, i}$. The particle mass $m_{\text {sep }}$, which was incorporated inside the cell before washing, cannot be detected directly. It therefore has to be calculated with data retrieved during the separation process according to

$$
m_{\mathrm{sep}}=c_{0} \cdot m_{0}-c_{f} \cdot m_{f}-c_{d} \cdot m_{d}
$$

It includes the feed mass concentration $c_{0}$, the feed suspension mass $m_{0}$, the filtrate mass concentration $c_{f}$, the filtrate suspension mass $m_{f}$, the drain mass concentration $c_{d}$, and drain suspension mass $m_{d}$. The drain suspension is the residual liquid that remains inside the filter cell after the magnetic separation step. The drain suspension is removed by backpumping before backwashing takes place.

Two theoretical models, namely the ideal displacement model (Ruslim 2008) and the ideal mixing-cell model from chemical process engineering (Levenspiel 1999), are suitable to compare with backwashing results of the HGM filter. The ideal displacement theory is based on an ideal plug flow and assumes that the washing liquid completely flushes out the magnetic particles. It defines that the relative residue is simply 


$$
r^{*}(W)=\frac{c}{c_{0}}=1-W .
$$

The mixing-cell model considers the flow behavior inside the cell volume. It assumes ideal mixing in each cell, which involves homogeneous distribution/dilution of the residue. With growing number of cells $N$ the flow pattern approaches an ideal plug flow. The relative residual concentration inside the filtration cell is

$$
r^{*}(W)=\frac{1}{N} \cdot \sum_{j=1}^{N} \sum_{i=0}^{j-1} \frac{(N \cdot W)^{i}}{i !} \cdot \exp (-N \cdot W) .
$$

A typical wash curve subdivides into three regimes. The first part $(W \leq 1)$ often approximates the ideal displacement curve. In the second section $(1<W \leq 3)$, mechanical dispersion (e.g., due to shear forces, turbulence) predominates and is best described by the mixing-cell model with the adjustment parameter $N$. The third region $(W>3)$ is characterized by diffusion, which is not considered by the two models and involves further declining of the wash curve slope.

\subsubsection{Method}

The filter loading takes place at $100 \mathrm{l} / \mathrm{h}$ with the same suspension as used for the separation efficiency tests. Before washing, the remaining mother liquor (drain suspension) is drained through the bottom of the HGMS cell, while the filter remains inside the magnetic field to avoid particle loss. Afterward, the washing process takes place in batches with the HGMS cell moved out of the Mandhala magnet as shown in Fig. 9.7.

The pressurized washing liquid (water at 2 bar, $\mathrm{pH} 7$ ) is injected through an array of three spraying nozzles at the top of the HGMS cell (see Fig. 9.4). Simultaneously, the matrix and/or impellers rotate clockwise or counter clockwise. All experiments were executed with a fixed opening time $t_{s}=0.35 \mathrm{~s}$ and closing time $T=0.1 \mathrm{~s}(P F R$ of $2.2 \mathrm{~Hz})$. Until the cell is filled the discharge valve at the bottom of the cell is closed. Then, the inflow stops while the matrices and/ or impellers keep rotating for two more minutes. Afterward, the suspension discharges through the bottom of the cell to a sample container at the maximum volume flow of $200 \mathrm{l} / \mathrm{h}$. This washing step is repeated several times.

\subsubsection{Experimental Results}

The analysis examines the backwashing behavior as a function of sole matrix or impeller rotation as well as the co-action of both, see Fig. 9.8. The results of sole matrix or impeller turning are shown in Fig. 9.8a. The diagram displays the wash curves of experiments with two different matrix rotational speeds (100 and $336 \mathrm{rpm})$ as well as with the maximum possible impeller velocity (171 rpm). The 


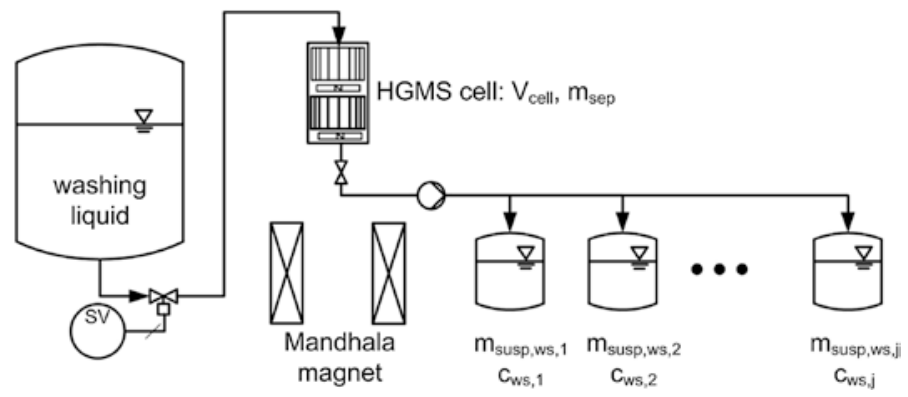

Fig. 9.7 Batchwise washing process with the HGMS cell moved out of the Mandhala magnet
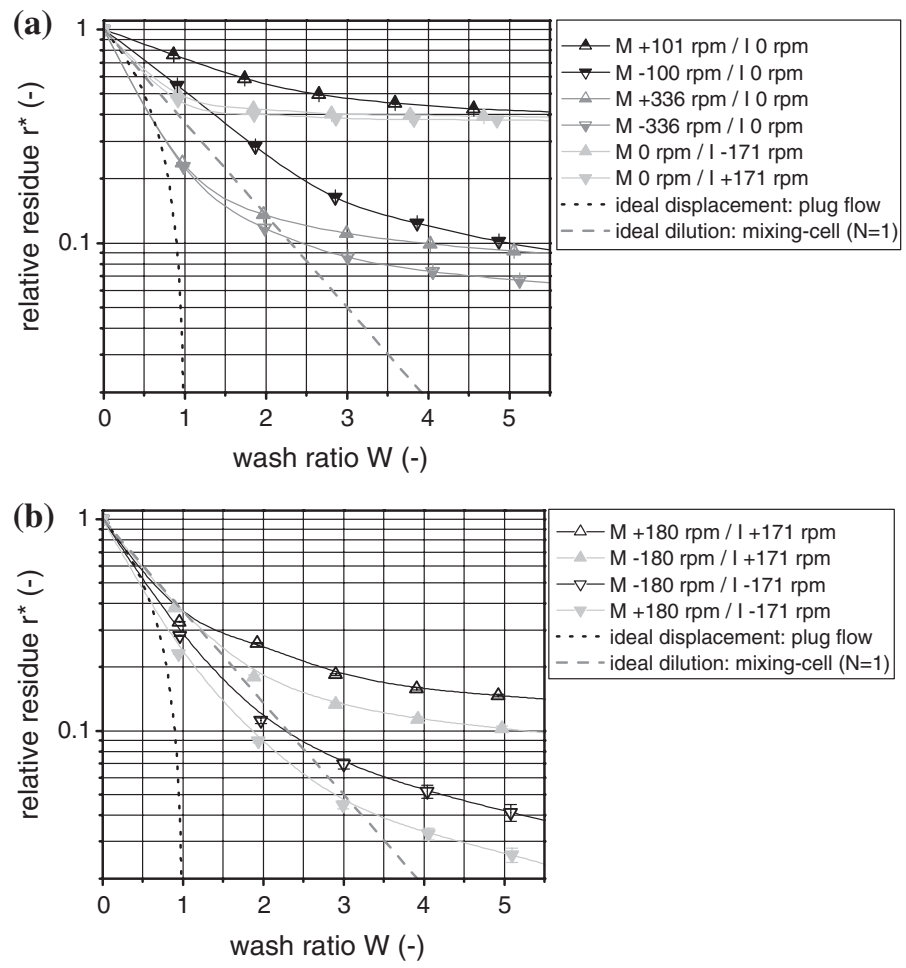

Fig. 9.8 Backwashing behavior as a function of rotational speed and sense of rotation of matrices $(M)$ and/or impellers $(I)$. The sense of rotation, considered from top view of the filter chamber, is indicated by + and - . It stand for clockwise and counter clockwise rotation, respectively. A comparison with ideal displacement and dilution models is given. a Solely using matrices $(M)$ or impellers $(I)$ rotation. b Simultaneously using matrix $(M)$ and impeller $(I)$ rotation

sense of rotation is indicated by + for clockwise and - for counter clockwise rotation considering the top view of the filter cell. The graph shows that solely operating the impellers, both counter clockwise and clockwise, results in a final 
unsatisfactory relative residue of 0.4 . Further, it can clearly be seen that the matrix revolution has a major impact residue than the impeller rotation on the decrease of the relative residue. The backwashing enhances with growing rotational speed. In addition, the sense of matrix rotation has an influence on the wash result, with clockwise rotation being better than counter clockwise rotation. The first two experiments presume that the influence of the sense of rotation is decreasing with growing rotational speed of the matrices.

The comparison of the wash diagrams in Fig. 9.8 reveals that an enhanced washing result can be achieved by simultaneous rotation of matrices and impellers. A clockwise rotation of the impellers $(\mathrm{I}+)$ is less effective than a counter clockwise rotation $(\mathrm{I}-)$. At the same time, the rotational sense of the matrices has no clear influence on the wash curve. The simultaneous revolution of impellers and matrices induces either concurrent or countercurrent flow. A concurrent flow occurs if both elements are turning in the same direction while opposite directions induce a countercurrent flow. Figure $9.8 \mathrm{~b}$ reveals that negative rotation of the impellers is more efficient than positive one and a countercurrent flow outperforms a concurrent one.

The comparison of the experimental wash curves in Fig. 9.8 with the theoretical models illustrates two effects. Some wash curves lie above the ideal dilution and displacement curve, which indicates that there are stagnant zones with little turbulence in the filter cell and the wash result is insufficient. Other wash results resemble the ideal displacement curve in the first regime $(W \leq 1)$ and are similar to the ideal dilution curve in the second region of the wash curve $(1<W \leq 3)$. This reveals good backwashing behavior. If the progression of the curve in the second regime $(1<W \leq 3)$ is steeper than that of the ideal dilution curve, the mixing-cell model can be adapted to a number greater than one. It indicates that considerable turbulence appears. With growing wash ratio $(W>3)$ the particle deposition layer on wall and separation matrices decreases. This involves that dispersion and diffusion limitations increasingly effect the wash result, which further declines the slope of the wash curve.

Concluding, the wash diagrams in Fig. 9.8 show the influence of rotational sense and speed of impellers and matrices. Their comparison with theoretical models indicates that the extent of raised turbulence is responsible for the quality of the wash result. The following analysis helps to elucidate the flow distribution and behavior in more detail.

\subsubsection{Flow Analysis and Discussion}

The filter apparatus has a glass wall and the flow pattern is visible by using glass beads suspended in water. The following section confines to schematic representation of the observed flow.

Figure 9.9 depicts the visual observations of the flow in case of either impeller or matrix rotation. The main difference is that the current is either directed axially upwards or downwards. The scheme illustrates that counter clockwise rotation of impellers (I-) in Fig. 9.9a (left) produces an upwards axial current, clockwise rotation of the impellers (I+) in Fig. 9.9b (left) causes a downwards axial 
(a)
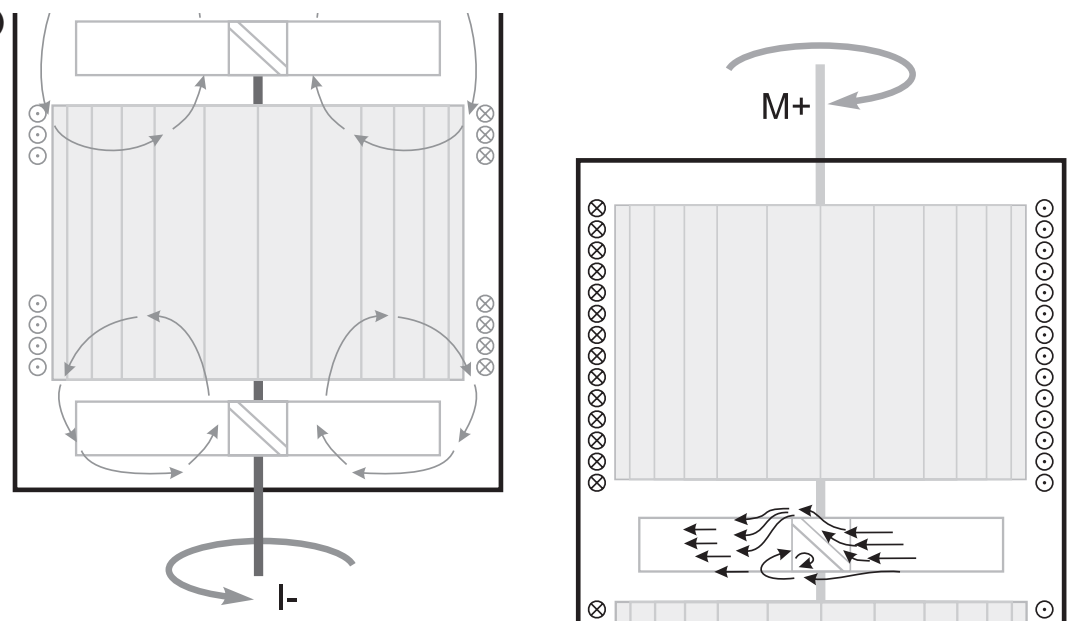

(b)
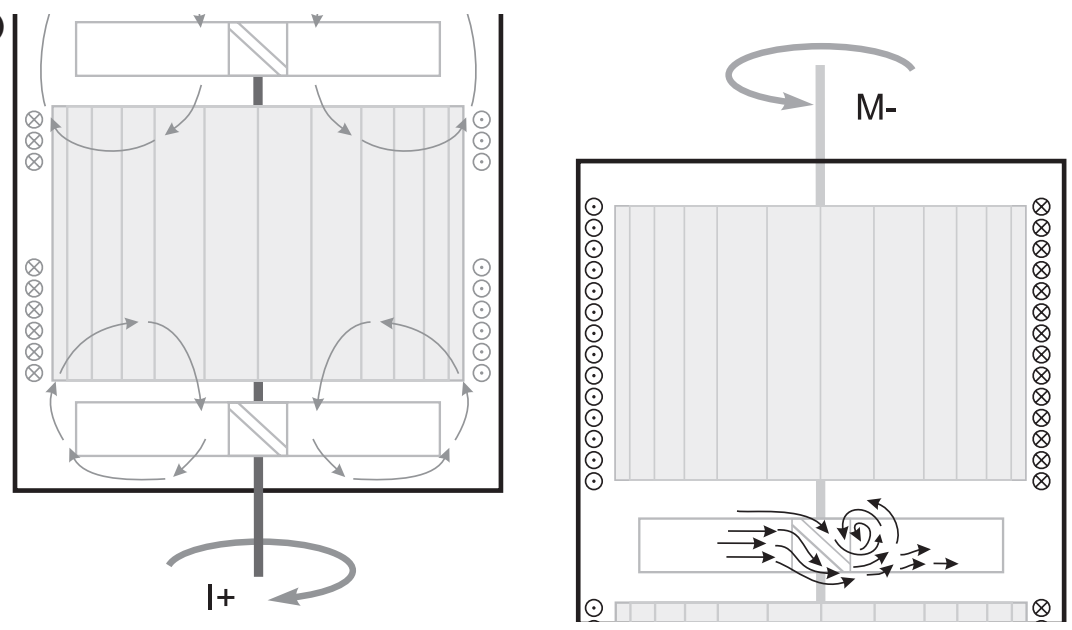

Fig. 9.9 Flow patterns of sole impeller or matrix rotation. The sense of rotation influences the axial flow direction. The inactive impellers serve as flow baffles, which induce turbulence. a Upwards axial current: counter clockwise impeller rotation $(I-)$ or clockwise matrix rotation $(M+)$. b Downwards axial current: clockwise impeller rotation $(I+)$ or counter clockwise matrix rotation $(M-)$

current. Due to the presence of the matrix elements a tangential flow results, which is indicated by arrows pointing from and into the drawing layer. The sole matrix revolution generates mainly a tangential current. The fluid rotates and develops a spout in case of a sufficiently high rotational speed of the matrices. The inactive impellers act as baffles and induce turbulence. A clockwise rotation of the matrices (M+), see Fig. 9.9a (right)) induces that the main flow passes above the impellers, then it drops down, which induces eddies behind the blades. Hence, the axial flow points upwards. A rotation in opposite direction (counter clockwise rotation 

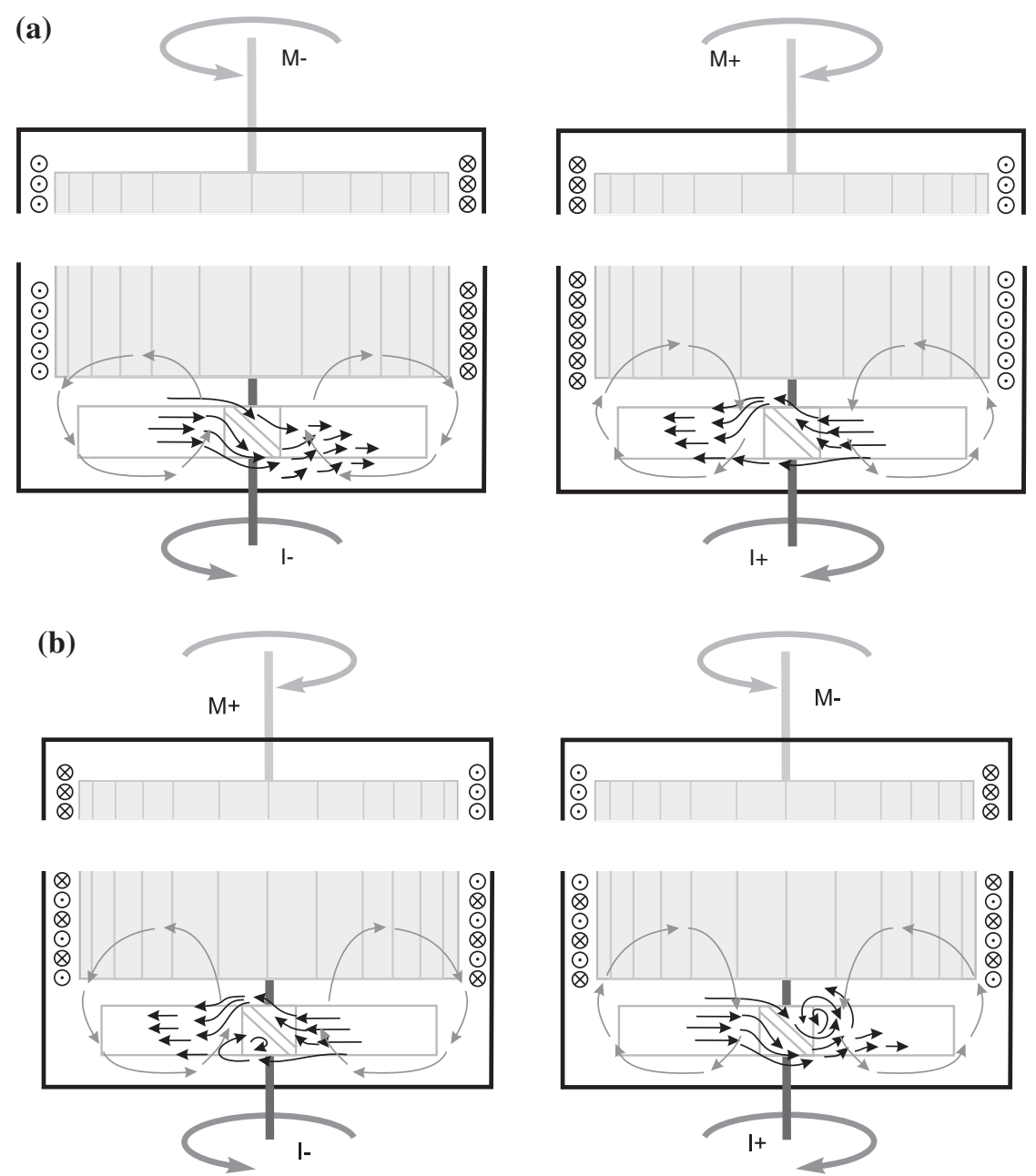

Fig. 9.10 Flow patterns of co-acting matrix and impeller rotation. a Concurrent rotation evokes that upwards axial flow superimposes downwards axial flow effects and vise-versa. b Countercurrent rotation enhances either upwards axial flow $(\mathrm{M}+/ \mathrm{I}-$ ) or downwards axial flow $(\mathrm{M}-/ \mathrm{I}+)$

of the matrices $(\mathrm{M}-$ ), see Fig. 9.9b (right)) causes the main flow to traverse underneath the pitched blades. A turbulent reverse flow develops behind the impellers' blades and the flow pattern reveals that downwards axial current arises.

The appropriate axial flow direction depends on the particle/fluid density difference: upwards axial current ( $\mathrm{I}-$ or $\mathrm{M}+$, see Fig. 9.9a) promotes the distribution of floating particles, whereas downwards axial current (I+ or $\mathrm{M}-$, see Fig. 9.9b) is most efficient for the resuspension of settling particles (Paul 2004).

Co-acting matrix and impeller rotation are subdividable into concurrent (see Fig. 9.10a) and countercurrent (see Fig. 9.10b) operation. Concurrent matrix and impeller rotation diminishes axial circulation and the fluid mainly moves radially 
and tangentially. The extent of reduction depends on the relative velocity between the rotating element. If they have approximately the same rotational speed, the pitched blade impellers do not act as baffles, but accelerate the fluid spout rotation. The flow pattern exhibit less eddies which proves that the shear forces are small and the wash results are poor. In case of countercurrent rotation of impellers and matrices, see Fig. 9.10b, the baffle effect of the impellers is enhanced compared to sole matrix rotation. The increased turbulence evokes shear forces, which support the particle detachment from the matrices, and the backwashing is more successful. In both cases it applies that due to the pitched blades of the impellers, their rotational sense determines the axial current direction: Upwards axial flow arises, when impellers are turned counter clockwise whereas downwards axial flow occurs for clockwise impeller rotation.

The observations of the flow in Figs. 9.9 and 9.10 are in accordance with the experimental results in Fig. 9.8. The analysis shows that countercurrent rotation produces more turbulence than concurrent rotation and therefore is best suited for backwashing. The axial flow direction is also depicted in Fig. 9.8: The downwards directed triangle symbols stand for downwards axial flow and the upwards directed triangle symbol represents upwards axial flow. In this work, the density of the used particles exceed that of the fluid and, as expected for settling particles, downwards axial flow is more efficient that upwards axial flow.

\subsection{Soy-Whey Protein Purification}

Soy-whey is a side stream from soy processing that contains an important protease inhibitor, called BBI. The inhibitor is known as agent against cancer and multiples sclerosis (Fournier et al. 1998). It is a monomeric protein containing 71 amino acids in a single polypeptide chain with seven internal disulfide bonds and an isoelectric point at $\mathrm{pH} 4.2$ (http://www.uniprot.org/uniprot/P01055). In SDS-PAGE ${ }^{2}$ analysis, it appears at $12 \mathrm{kDa}$. The protein is highly stable against, e.g., high temperature and extreme $\mathrm{pH}$ and can be efficiently adsorbed from anion exchange resins above its isoelectric point. Conventional downstream processing is laborious and expensive as numerous process steps are required (Birk 1961) and is therefore not yet applied at large scale. This work presents the attempt to purify BBI from soy-whey with economic anion exchange magnetic particles. It proves if it is advantageous to additionally perform a treatment with washing buffer before elution in order remove residual sugar.

\subsubsection{Methods}

As stated in Sect. 9.4 only Orica Watercare MIEX® DOC resin were available in sufficient quantity for large-scale experiments. The Orica MIEX® DOC particles $\left(m_{p}=110 \mathrm{~g}\right)$ are stored in aqueous liquid that contains $20 \%$ ethanol. SOLAE,

${ }^{2}$ Sodium dodecyl sulfate polyacrylamide gel electrophoresis. 
Denmark kindly provided frozen natural and pretreated soy-whey (Charge: 20121022-001EE). The following section summarizes the used methods, which are applied for soy-whey protein purification.

\subsubsection{Soy-Whey Pretreatment}

The pretreatment facilitates the subsequent purification, which applies magnetic support with an anion exchange functionalization. It includes a heat conditioning at $80{ }^{\circ} \mathrm{C}$ and a removal of cationic protein components with $1 \mathrm{~g} / 1$ LiChroprep ${ }^{\circledR}$ Si 60 resin from Merck (adsorption time is $15 \mathrm{~min}$ ). The silica particles and precipitates are separated by decanter centrifugation. For further removal of fines and microorganisms, a subsequent filtration step $(0.2 \mu \mathrm{m})$ is necessary. Finally, the pretreated soy-whey is preserved with Proclin ${ }^{\circledR}$.

\subsubsection{Process Description}

The standard operating procedure (SOP) of the experiments is shown in Fig. 9.11. It depicts that at the beginning, possible residues that adhere on the particles' surface have to be eluted. Then the magnetic beads are washed and transferred to the soy-whey. In more detail, this requires the following steps:

(1) Transfer to elution buffer $\left(m_{0}=21: 20 \mathrm{mM}\right.$ Tris- $\mathrm{HCl} @ \mathrm{pH} 7.0$ and $\left.1 \mathrm{M} \mathrm{NaCl}\right)$.

(2) Transfer to washing buffer $\left(m_{0}=21: 20 \mathrm{mM}\right.$ Tris-HCl $@ \mathrm{pH}$ 7.0).

(3) Transfer to pretreated soy-whey $\left(m_{0}=5.51: c_{0}=20 \mathrm{~g} / \mathrm{l}\right) \mathrm{pH}$ adjusted to 7.0 by $2 \mathrm{M} \mathrm{HCl}$ or $\mathrm{NaOH}$.

Each transfer comprises of removing the supernatant, draining of the separation cell, resuspension, and equilibration. The removal of the supernatant is done by magnetic separation. The volume flow through the magnetic filter cell is $50 \mathrm{l} / \mathrm{h}$, which corresponds to $1.77 \mathrm{~mm} / \mathrm{s}$ undisturbed flow rate. The resuspension with either washing liquid, elution buffer or soy-whey takes place within the backwashing step. Countercurrent matrix and impeller rotation $(\mathrm{M}+180 \mathrm{rpm} / \mathrm{I}-$ $171 \mathrm{rpm}$ ) is applied, which has proven to be most efficient (see Sect. 9.4.2). The wash ratio lies between 1.7 when applying 21 of washing liquid or elution buffer and 4.5 if 5.51 of soy-whey is used. Then, the relative residue is below 0.15 and 0.03 , respectively. Afterwards, $10 \mathrm{~min}$ of equilibration allow the molecules to diffuse into or out of the porous Orica MIEX® DOC particle system.

The bound target protein is isolated by (multiple) elution. The chart in Fig. 9.11 depicts that it is possible to introduce a previously (multiple) treatment with washing buffer to remove residues. On completion of the purification, the particles are transferred to storage liquid and kept at $6{ }^{\circ} \mathrm{C}$.

The system performance tests in Sect. 9.4 involved the measurement and evaluation of the values indicated as bold symbols in Fig. 9.11. In contrast, the purification experiments focus on the determination of the total protein $c_{\mathrm{TP}}$ and the sugar 


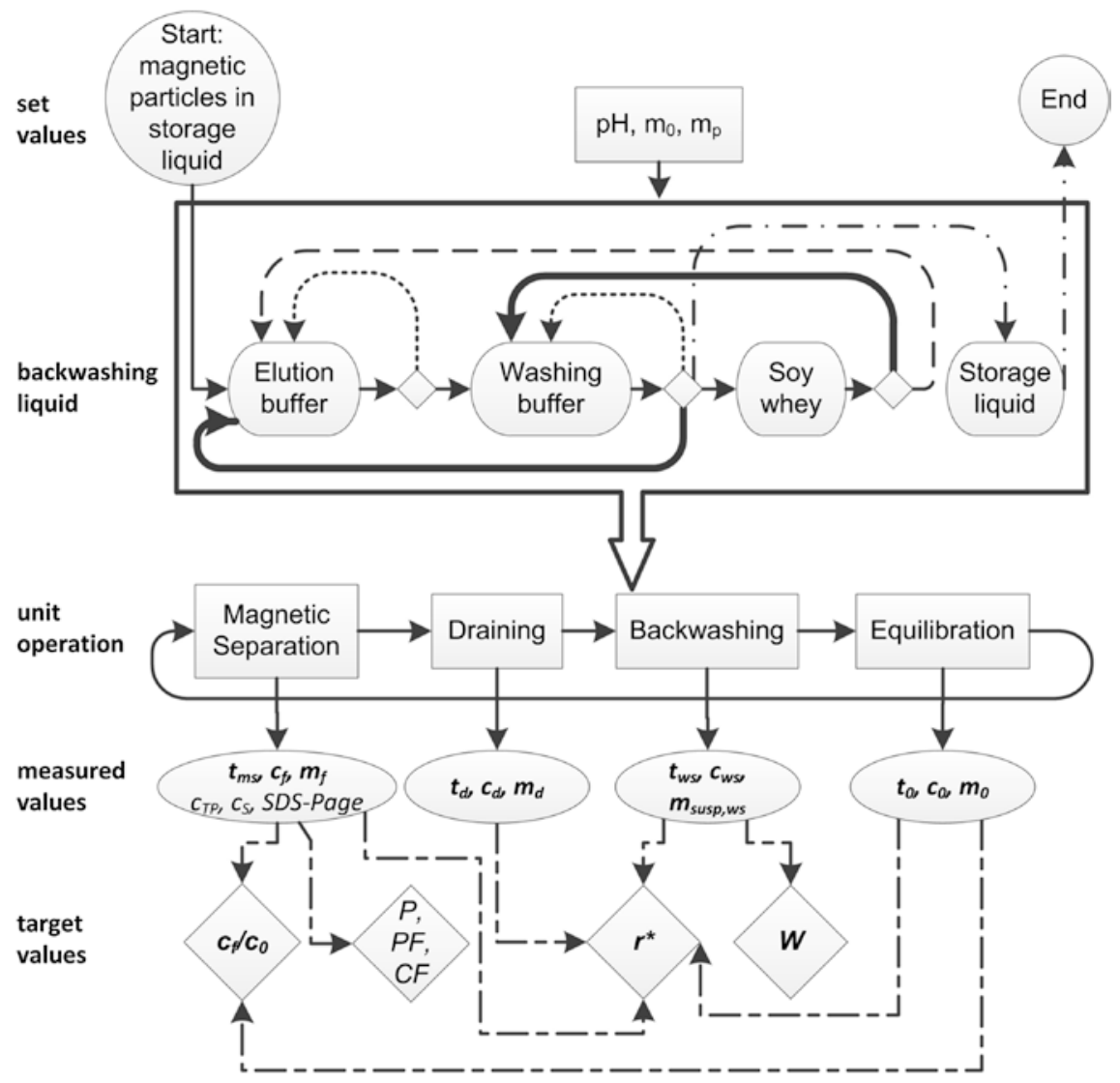

Fig. 9.11 Standard operating procedure of the experiments

content $c_{S}$ as well as on target protein purity $P$, purification factor PF, and its concentration factor $\mathrm{CF}$ of the target protein SDS-PAGE. The determination of these data is described below.

\subsubsection{Determination of Total Protein Content}

The amount of total protein in each process stream is determined by a standard protein assay, namely bicinchoninic acid [2,2'-diquinolyl-4,4'-dicarboxylic acid (BCA)] assay using bovine serum albumin (BSA) $(0-2 \mathrm{mg} / \mathrm{mL})$ as a standard protein. Solved $\mathrm{Cu}(\mathrm{II})$ ions react with the proteins to $\mathrm{Cu}(\mathrm{I})$ ions, which again form a purple complex with BCA, a highly specific chromogenic reagent for $\mathrm{Cu}(\mathrm{I})$ (Biuret reaction) (Smith et al. 1985). Its absorbance maximum is at $562 \mathrm{~nm}$ (Ötleş 2012). The BCA kit for Protein Determination (BCA1) is supplied by Sigma-Aldrich Co. LLC. 


\subsubsection{Determination of Sugar Content}

The enzymatic analysis based on photometry is appropriate to determine the amount of sugar in food with high specificity. If the sample is sufficiently diluted, the Lambert-Beer law is applicable. Soybean's sugar mainly consists of sucrose and stachyose (Hou et al. 2009). As stachyose is indigestible by humans and animals, the food and feed processing industry developed soybeans with high content of sucrose and low content of stachyose. Therefore, the analysis of stachyose is omitable and the sucrose/D-fructose/D-glucose kit (K-SUFRG) by Megazyme, Ireland is adequate. The principle is explained in the assay procedure of the manufacturer (http://secure.megazyme.com).

\subsubsection{Monitoring the Purification Process by Sodium Dodecyl Sulfate Polyacrylamide Gel Electrophoresis (SDS-PAGE)}

The analysis is performed with an electrophoresis cell unit, a precast gradient gel (4-20\%), modified Lämmli sample buffer (Roti-Load 1), prestrained 10-150 kDa marker, and analytic grade chemicals supplied by Roth $\mathrm{GmbH}$, Karlsruhe, Germany. The principle is explained in the assay procedure of the manufacturer. The BBI standard, chymotrypsin-trypsin inhibitor (T9777), is supplied by SigmaAldrich Co. LLC.

The purity $P$ of the target protein is determined by SDS-PAGE. The amount of a stain associated with the target band is referred to the amount of the stain associated with all the bands on the gel as proposed by Burgess (2009). The amount of stained protein equals the relevant peaks area within the densitogram. Hence, the purity is

$$
P=\frac{A_{\mathrm{BBI}}}{A_{t}}
$$

with the $\mathrm{BBI}$ peak area $A_{\mathrm{BBI}}$ and the total integral of the densitogram $A_{t}$. An ordinary office scanner captures the gel, then the image file is converted to gray scale and processed to get the densitograms. A calibration with the marker and background subtraction takes place.

The purification factor PF is given by the purity of the sample (unbound or eluate) in relation to the purity of the soy-whey (feed). If the PF is bigger than one, it expresses that purification has taken place.

The concentration factor $\mathrm{CF}$ describes the fraction of BBI content in the sample $c_{\mathrm{BBI}, i}(\mathrm{i}$ : unbound, washing or eluate) related to the $\mathrm{BBI}$ concentration of the original soy-whey $c_{\mathrm{BBI}, \mathrm{sw}}$

$$
\mathrm{CF}=\frac{c_{\mathrm{BBI}, i}}{c_{\mathrm{BBI}, \mathrm{sw}}} .
$$

In order to evaluate the BBI concentration of the soy-whey, unbound and eluate samples, a calibration with the BBI standard concentration series takes place. It is 
assumed that the standard is $100 \%$ pure. The concentration of the standard solution is related to BBI target band area, which increases exponentially with the concentration. Afterwards, the content of the unknown samples (soy-whey, unbound, eluate) can be calculated.

\subsubsection{Protein Purification Results and Discussion}

The first purification experiment simply included adsorption and elution. The following experiments prove if it is advantageous to additionally wash the particles before the elution of the target molecules. It is investigated if a multistep washing and thereafter a multistep elution optimizes the purification result with respect to residual protein and sugar content.

\subsubsection{Purification Without Washing}

The experiment was executed according to the SOP in Fig. 9.11 using Orica MIEX ${ }^{\circledR}$ DOC particles and pretreated soy-whey. The determination of total protein concentration, sucrose content, and SDS-PAGE analysis characterizes the purification process. The results are summarized in the purification summary table (PST), see Table 9.1.

The pretreated soy-whey $(5.5 \mathrm{l})$ contains $1.958 \mathrm{~g} / \mathrm{l}$ of total protein, the supernatant (unbound, approx. $5.5 \mathrm{l}$ ) holds $0.952 \mathrm{~g} / \mathrm{l}$ protein and the purified eluate (approx. 2 1) includes $1.405 \mathrm{~g} / \mathrm{l}$ protein. As expected, the sugar assay showed that D-glucose and D-fructose content is below the detection limit and therefore both are omitted. The sucrose content in the pretreated soy-whey is $12.05 \mathrm{~g} / \mathrm{l}$. Although about $87 \%$ of the sucrose content is separated with the unbound fraction, $7 \%$ residual is measured in the eluate. The mass balance reveals that protein and sucrose are lost during the separation. It is assumed that this is due to unconsidered drained fraction and due to residue of protein and sucrose molecules, which still adhere to the magnetic particles' surface after elution.

The electrophoresis scan, see Fig. 9.12, monitors the purification process and enables the evaluation of the purity, the purification factor, and the concentration factor, which are presented in Table 9.1. It shows that the pretreated soy-whey (L1) still contains different impurities beside the target BBI at $12 \mathrm{kDa}$, e.g., the Kunitz inhibitor (KI) at $21 \mathrm{kDa}$. Due to the pretreatment, it exhibits a purity of $50 \%$. The unbound fraction (L2) depicts the loss of BBI and the separation of protein bigger than $30 \mathrm{kDa}$. The eluate in lane L3 still incorporates $\mathrm{KI}$ and residue of protein bigger than $30 \mathrm{kDa}$ and its purity is $65 \%$, which is equivalent to a purification factor of 1.3. The eluate's concentration factor of 1.5 shows that the target protein has been concentrated. Additionally, the eluate is diluted with distilled water with ratios (1:1), (1:2), (1:4) (L4-L6). The concentration factor of L4 is halved to 0.7 and quartered to 0.4 for L5. The more the eluate is diluted, the 
Table 9.1 Purification summary table with pretreated soy-whey

\begin{tabular}{l|l|l|l|l|l}
\hline Step & $\begin{array}{l}\text { Total protein } \\
c_{\mathrm{TP}}(\mathrm{g} / \mathrm{l})\end{array}$ & $\begin{array}{l}\text { Sucrose }{ }^{4} c_{S} \\
(\mathrm{~g} / \mathrm{l})\end{array}$ & Purity ${ }^{5}(\%)$ & $\begin{array}{l}\text { Purification } \\
\text { factor }^{5} \mathrm{PF}(-)\end{array}$ & $\begin{array}{l}\text { Concentration } \\
\text { factor }^{5} \mathrm{CF}(-)\end{array}$ \\
\hline $\begin{array}{l}\text { L1: pretreated } \\
\text { soy-whey }\end{array}$ & 1.958 & 12.05 & 50 & 1 & 1 \\
\hline L2: unbound & 0.952 & 10.51 & 30 & 0.6 & 0.5 \\
\hline L3: eluate & 1.405 & 2.23 & 65 & 1.3 & 1.5 \\
\hline $\begin{array}{l}\text { L4: eluate } 1: 1 \\
\text { dilution }\end{array}$ & n.d. & n.d. & 64 & 1.3 & 0.7 \\
\hline $\begin{array}{l}\text { L5: eluate } 1: 2 \\
\text { dilution }\end{array}$ & n.d. & n.d. & 78 & 1.6 & 0.4 \\
\hline $\begin{array}{l}\text { S1: BBI } \\
(0.2 \mathrm{~g} / \mathrm{l})\end{array}$ & n.d. & n.d. & 45 & 0.9 & 11.8 \\
\hline $\begin{array}{l}\text { S2: BBI } \\
(0.1 \mathrm{~g} / \mathrm{l})\end{array}$ & n.d. & n.d. & 60 & 1.2 & 5.9 \\
\hline $\begin{array}{l}\text { S3: BBI } \\
(0.05 \mathrm{~g} / \mathrm{l})\end{array}$ & n.d. & n.d. & 81 & 1.6 & 3 \\
\hline $\begin{array}{l}\text { S4: } \mathrm{BBI} \\
(0.025 \mathrm{~g} / \mathrm{l})\end{array}$ & n.d. & n.d. & 85 & 1.7 & 1.5 \\
\hline
\end{tabular}

n.d. not determined

${ }^{3}$ Protein concentration determined by BCA assay using BSA $(0-2 \mathrm{mg} / \mathrm{ml})$ as a standard protein, see Sect. 9.5.1.3

${ }^{4}$ Sucrose content determined as described in Sect. 9.5.1.4

${ }^{5}$ Purity $P$, purification factor $\mathrm{PF}$ and concentration factor $\mathrm{CF}$ of target protein (BBI at approx. $12 \mathrm{kDa}$ ) measured as described in Sect. 9.5.1.5

Fig. 9.12 Purification followed up by SDS-PAGE. $M$ Marker, $L 1$ pretreated soy-whey (feed), L2 unbound (filtrate), L3 eluate, L4 diluted eluate $1: 1, L 5$ diluted eluate $1: 2$, L6 dilute eluate $1: 4, S 1-S 4$ BBI standard in different concentrations $S 1$ $0.2 \mathrm{~g} / \mathrm{l}, S 20.1 \mathrm{~g} / \mathrm{l}, S 30.05 \mathrm{~g} / \mathrm{l}$, S4 $0.025 \mathrm{~g} / 1$



more the apparent purity increases. It was impossible to evaluate L6 owing to the overlap of lane S1. The BBI standard exhibits residue of various other proteins, as shown in lanes $\mathrm{S} 1$ to $\mathrm{S} 4$, its purity is between 45 and $85 \%$. The lanes L3 and S4 both feature the same concentration factor, but the purity of the BBI standard is $20 \%$ higher than that of the eluate. 
The experiment shows that although some purification takes place, a selective separation of the protein is not possible due to the particle's nonselective surface modification. The lack of economic particles that selectively bind BBI is therefore the main obstacle of the process. Further, protein and sucrose that adhere to the particles was lost in the process.

\subsubsection{Purification Optimization}

The following experiments investigate the influence of repeatedly washing and elution. Untreated soy-whey is used as pretreated soy-whey stock had run out. The first experiment, labeled "w/o wash," is a repetition of the test in Sect. 9.5.2.1, which does not include washing and has only one elution step. The second trial "wash once" involves one washing step and three elution runs. Finally, in the third examination "wash twice" the particles are washed twice before they are eluted three times. Figure 9.13 collate the results of the three experiments. It presents the relative loss or gain of total protein and amount of sucrose of each process step in relation to the amount found in untreated soy-whey.

The unbound fraction (U) contains between 48.8 and $55.9 \%$ of total protein and between 89.2 and $92.7 \%$ sucrose compared to the untreated soy-whey, respectively. The eluate (E1) of the "w/o wash" experiment contains $8 \%$ sucrose at maximum protein yield of $(27.5 \pm 3.1) \%$. Both values are in good accordance to the results in Sect. 9.5.2.1. In "wash once" and "wash twice", the total protein loss in washing step one (W1) is approx. $4 \%$. It further decreases in washing step two (W2) to $1.7 \pm 0.04 \%$. At the same time, the sucrose content drops to $8 \%(\mathrm{~W} 1)$ and in case

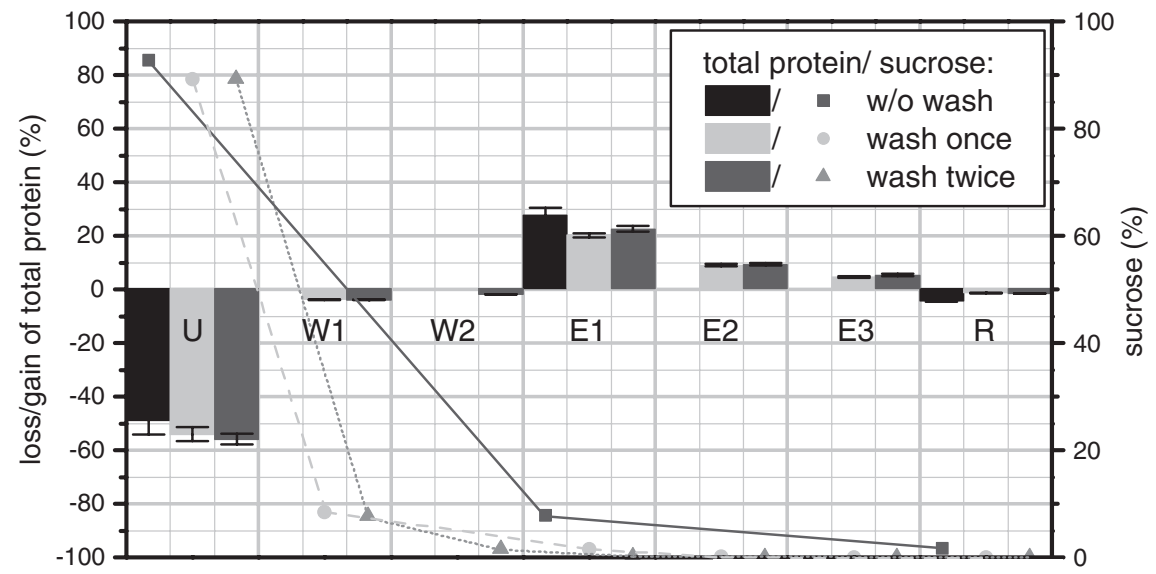

Fig. 9.13 Total protein loss or gain (BCA assay) and amount of sucrose in relation to the amount found in untreated soy-whey. $U$ filtrate of magnetic separation (5.5 1 unbound soywhey), W1/2 washing step 1 and 2 with 21 of washing buffer each, E1/2/3 elution step 1, 2 and 3 with 21 of elution buffer and $R$ regeneration with 21 washing buffer 


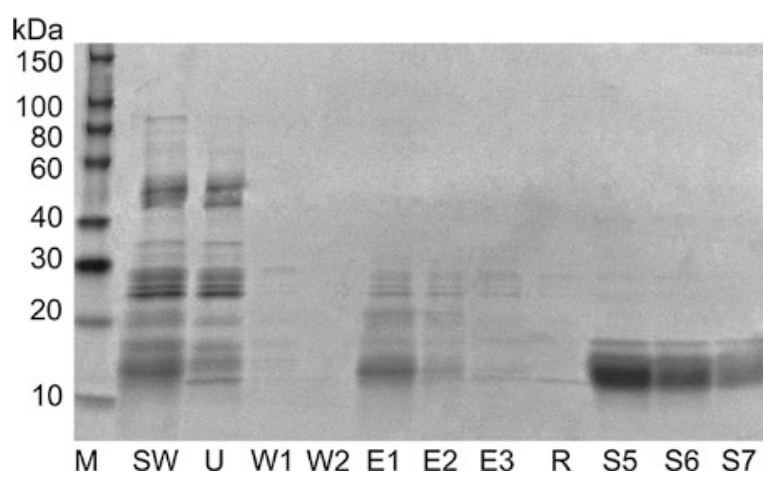

Fig. 9.14 Optimized purification, labeled as "wash twice" experiment, monitored by SDS-PAGE. $M$ Marker, SW 5.51 untreated soy-whey (feed), $U 5.51$ of unbound soy-whey, W1/2 washing step 1 and 2 with 21 of washing buffer each, E1/2/3 elution step 1,2, and 3 with 21 of elution buffer and $R$ regeneration with 21 washing buffer. $S 5-S 7$ BBI standard in different concentrations $S 5$ $0.02 \mathrm{~g} / 1, S 60.01 \mathrm{~g} / 1, S 70.005 \mathrm{~g} / 1$

of repeated washing runs to $1.5 \%$ (W2). Thereafter, the protein content in eluate E1 exceeds $20 \%$, which is only slightly less than in case of the "w/o wash" experiment. The additional protein yield in elution step E2 (10\%) and E3 (5\%) compensate this initial loss, which is due to the additional washing. Moreover, the sucrose content in all eluate's fraction is minimized to less than $3 \%$. In the regeneration step (R) the particles are treated with washing buffer in order to charge their surface with anions and prepare them for the next binding step. The both assays showed that only marginal amount of protein and sucrose is found in the washing buffer supernatant (R). The highest total protein yield (approx. $35 \%$ ) with lowest sucrose content (less than $3 \%$ ) is achieved when the process includes two washing steps and three elution steps as in the "wash twice" experiment. The results show the positive effect of washing before the elution. The sugar is removed, however some protein is lost.

The "wash twice" experiment was analyzed in more detail performing a SDSPAGE. Figure 9.14 shows the stained gel and the purification summary table in Table 9.2 condenses the results of total protein and sucrose analysis as well as the BBI purity and concentration evaluation. The natural soy-whey (SW) lane exhibits $\mathrm{BBI}$ at $12 \mathrm{kDa}$ and a lot of stained protein peaks up to $100 \mathrm{kDa}$. Its BBI purity is $33 \%$, which is $17 \%$ less than the pretreated soy-whey. The unbound (U) lane incorporates the proteins that did not adsorb to the Orica MIEX® DOC particles' surface. It contains most of the impurities of the soy-whey, therefore its purity is only $23 \%$. At the same time, the low intensity of the BBI band indicates that the target protein especially has been bound to the particles. The lanes W1 and W2 confirm that only a marginal amount of protein is lost due to the additionally performed washing runs. The analysis of the densitogram showed that the stained bands W1 and W2 vanish within the gel background intensity and they are therefore below the detection limit. The elution lane E1 indicates that the BBI peak almost has the same intensity than in the SW lane. The protein bands are 
Table 9.2 Purification summary table (PST) with untreated soy-whey of the experiment "wash twice"

\begin{tabular}{l|l|l|l|l|l}
\hline Step & $\begin{array}{l}\text { Total protein } \\
c_{\text {TP }}(\mathrm{g} / \mathrm{l})\end{array}$ & $\begin{array}{l}\text { Sucrose } \\
(\mathrm{g} / \mathrm{l})\end{array}$ & Purity ${ }^{5} P(\%)$ & $\begin{array}{l}\text { Purification } \\
\text { factor }\end{array}$ & $\begin{array}{l}\text { Concentration } \\
\text { factor }^{5} \mathrm{CF}(-)\end{array}$ \\
\hline $\begin{array}{l}\text { SW: untreated } \\
\text { soy-whey }\end{array}$ & $2.7 \pm 1.6 \%$ & 4.8 & 33 & 1 & 1 \\
\hline U: unbound & $1.5 \pm 3.3 \%$ & 4.4 & 23 & 0.7 & 0.5 \\
\hline W1: wash 1 & $0.3 \pm 4.3 \%$ & 1 & b.d.l. & - & - \\
\hline W2: wash 2 & $0.1 \pm 1.4 \%$ & 0.2 & b.d.l. & - & - \\
\hline E1: eluate 1 & $1.6 \pm 4.3 \%$ & 0.02 & 55 & 1.7 & 0.8 \\
\hline E2: eluate 2 & $0.7 \pm 4.3 \%$ & b.d.l. & 55 & 1.7 & 0.4 \\
\hline E3: eluate 3 & $0.4 \pm 10.0 \%$ & b.d.l. & 33 & 1 & 0.3 \\
\hline R: regeneration & $0.1 \pm 0.9 \%$ & b.d.l. & b.d.l. & - & - \\
\hline $\begin{array}{l}\text { S5: BBI } \\
(0.02 \text { g/l) }\end{array}$ & n.d. & n.d. & 81 & 2.5 & 1.7 \\
\hline $\begin{array}{l}\text { S6: BBI } \\
(0.01 \mathrm{~g} / \mathrm{l})\end{array}$ & n.d. & n.d. & 95 & 2.9 & 1.3 \\
\hline $\begin{array}{l}\text { S7: BBI } \\
(0.005 \mathrm{~g} / \mathrm{l})\end{array}$ & n.d. & n.d. & 95 & 2.9 & 0.8 \\
\hline
\end{tabular}

n.d. not determined

b.d.l. below detection limit

visible up to $30 \mathrm{kDa}$, though less intense than in the natural soy-whey lane, and those larger than $30 \mathrm{kDa}$ disappear completely. The eluate (E1) exhibits a purity of $55 \%$, which corresponds to 1.7 fold purification. The concentration factor is 0.8 , which means that dilution takes place. This issue has to be addressed and optimized in further work. In E2 the intensity of the stained bands decreases, but $\mathrm{BBI}$ is still the most intensive band with same purity that E1, but the concentration factor is halved. Elution E3 and regeneration R only contain sparse stained protein bands. The BBI standard lines S5, S6, and S7 are a concentration series of 0.02, 0.01 , and $0.005 \mathrm{~g} / \mathrm{l}$. The chosen dilutions are more appropriate than those in the first trial, see Fig. 9.12. The residual bands bigger than $20 \mathrm{kDa}$ disappear almost completely and the apparent purity is larger $80 \%$. The intensity of the BBI band in S7 is in the same range than that in SW and E1 lanes, which proves that the concentration of BBI in those streams is about $0.005 \mathrm{~g} / \mathrm{l}$.

The untreated soy-whey shows $2.7 \mathrm{~g} / \mathrm{l}$ of total protein and the sucrose concentration is $4.8 \mathrm{~g} / \mathrm{l}$. In the first cycle, the supernatant (unbound) holds $1.5 \mathrm{~g} / \mathrm{l}$ protein and $4.4 \mathrm{~g} / \mathrm{l}$ sucrose. The total protein analysis confirms the SDS-PAGE results, which stated that the protein loss due to washing is low. At the same time, the sucrose content is significantly reduced. The purified eluate (E1) contains $0.02 \mathrm{~g} / 1$ sucrose, which is only $2 \%$ of the amount that would be present if washing is omitted. In eluate E2 and E3 as well as in the regeneration supernatant (R) it is below the detection limit. Further, the total protein content in eluate E1 is $1.6 \mathrm{~g} / \mathrm{l}$ and decreases to $0.7 \mathrm{~g} / \mathrm{l}$ in $\mathrm{E} 2$ and $0.4 \mathrm{~g} / \mathrm{l}$ in E3. The separated regeneration liquid hold $0.4 \mathrm{~g} / \mathrm{l}$ total protein. 
The process shows that a multistep elution increases the yield and the residual sucrose amount is removable before elution by additionally performing one or two washing steps. The results draw the conclusion that the pretreatment of soy-whey as proposed in Sect. 9.5.1.1 might be omitted. The application of ion-exchange magnetic particles (e.g., Orica MIEX® DOC) can serve as a pretreatment of the natural soy-whey. Thereafter, it is necessary to use more selective magnetic carrier particles (e.g., by a BBI-antibody functionalization) for further polishing of the target protein, which enhance the purity and the concentration factor.

\subsection{Conclusion}

The chapter analyzes the performance of the new pilot scale HGMS filter that is equipped with a rotatable matrices and impellers regarding its separation efficiency and backwashing characteristics. Its application for protein purification was successful. However, a selective separation of BBI is not possible with anion exchange magnetic particles. The lack of economic particles that selectively bind $\mathrm{BBI}$ is therefore the main obstacle of the process. Both the permanent magnet and the separation cell of the new design exhibit favorable characteristics to promote the principle for large-scale separation processes in industry. First, they both are easily scalable or parallelizable. Second, they exhibit a reasonable investment, and operational costs are low because no power supply is required for the magnet. The field corresponds to that of conventional magnet systems and more than sufficient for HGMS. Third, the separation unit is very compact and light as compared to conventional permanent magnets or electromagnet devices.

Acknowledgments This work has been carried out during the EU project "MagPro'Life" at the Institute of Mechanical Process Engineering and Mechanics (MVM), Karlsruhe Institute of Technology (KIT). The authors owe special thanks for EU by Helmut Soltner (Forschungszentrum Jülich $\mathrm{GmbH}$, Central Institute of Engineering, Electronics and Analytics (ZEA-1)) funding under contract FP7-NMP, 229335. We would like to acknowledge the helpful advises and material supply by Christian F. Nielson and Niels Daalgard (Solae LLC). Anja Pauls (Institute of Functional Interfaces, KIT), Johannes Lindner and Ellen Hildebrand (both MVM, KIT) supported the SDSPAGE analysis. The design and construction of the magnet as well as the separation cell was mainly assisted by Hans Guigas and Thomas Reutter (MVM, KIT).

\section{References}

All FEM calculations were performed with the AC/DC module of the COMSOL Multiphysics. www.comsol.com (COMSOL 4.3 a)

Becker J, Thomas O, Franzreb M (2009) Protein Separation with magnetic adsorbents in micellar Aqueous Two-Phase Systems. Sep Purif Technol 65:46-53. doi:10.1016/j.seppur.2008.05.017

Birk Y (1961) Purification and some properties of a highly active inhibitor of trypsin and $\alpha$-chymotrypsin from soybeans. Biochim Biophys Acta 54(2):378-381. doi:10.1016/00063002(61)90387-0 
Burgess R (2009) Preparing a purification summary table. Methods Enzymol 463:29-34. doi:10.1016/S0076-6879(09)63004-4

Foster I, Millington R, Grew R (1992) The impact of particle size controls on stream turbidity measurement; some implications for suspended sediment yield estimation. In: Erosion and sediment transport monitoring programmes in river basins: proceedings of the Oslo symposium, vol 210, pp 51-62

Fournier D, Erdman J Jr, Gordon G (1998) Soy, its components, and cancer prevention: a review of the in vitro, animal, and human data. Cancer Epidemiol Biomarkers Prev 7(11):1055-1065

Gerber R, Birss R (1983) High gradient magnetic separation. Research Studies Press, chichester

Hou A, Chen P, Alloatti J, Li D, Mozzoni L, Zhang B, Shi A (2009) Genetic variability of seed sugar content in worldwide soybean germplasm collections. Crop Sci 49(3):903-912. doi:10. 2135/cropsci2008.05.0256

Kaeppler T, Cerff M, Ottow K, Hobley T, Posten C (2009) In situ magnetic separation for extracellular protein production. Biotechnol Bioeng 102(2):535-545. doi:10.1002/bit.22064

Levenspiel O (1999) Chemical reaction engineering, 3rd edn. Wiley, New York

Lewis J (1996) Turbidity-controlled suspended sediment sampling for runoff-event load estimation. Water Resour Res 32(7):2299-2310. doi:10.1029/96WR00991

Lindner J, Wagner K, Eichholz C, Nirschl H (2010) Efficiency optimization and prediction in high-gradient magnetic centrifugation. Chem Eng Technol 33(8):1315-1320. doi:10.1002/ceat.201000112

Megazyme International Ireland (2012) Sucrose, D-fructose and D-glucose assay procedure (K-SUFRG). http://secure.megazyme.com. Accessed 29 Sep 2013 (Archived by Website at http://www.webcitation.org/6K010V8xJ)

Menzel K, Windt CW, Lindner JA, Michel A, Nirschl H (2013) Dipolar openable Halbach magnet design for High-Gradient Magnetic Filtration. Sep Purif Technol 105:114-120. doi:10.1016/j.seppur.2012.12.019

Menzel K, Lindner JA, Soltner H, Nirschl H (2014) Design and application of a longitudinal field Aubert magnet composed of identically shaped blocks for large-scale magnetic separation, submitted to Sep Purif Technol in June 2014 (to be published)

Ötleş S (ed) (2012) Methods of analysis of food components and additives, 2nd edn. Chemical \& functional properties of food components. Taylor \& Francis, Boca Raton

Paul EL (ed) (2004) Handbook of industrial mixing: science and practice. Wiley-Interscience, Hoboken

Raich H, Blümler P (2004) Design and construction of a dipolar Halbach array with a homogeneous field from identical bar magnets: NMR mandhalas. Concepts Magn Reson Part B Magn Reson Eng 23(1):16-25. doi:10.1002/cmr.b.20018

Ruslim F (2008) Flow phenomena in cake washing driven by mass forces. Ph.D. thesis, University of Karlsruhe, Germany, ISBN 978-3-86727-788-4

Ruslim F, Hoffner B, Nirschl H, Stahl W (2009) Evaluation of pathways for washing soluble solids. Chem Eng Res Des 87(8):1075-1084. doi:10.1016/j.cherd.2009.01.007

Smith P, Krohn R, Hermanson G, Mallia A, Gartner F, Provenzano M, Fujimoto E, Goeke N, Olson B, Klenk D (1985) Measurement of protein using bicinchoninic acid. Anal Biochem 150(1):76-85. doi:10.1016/0003-2697(85)90442-7

Soltner H, Blümler P (2010) Dipolar Halbach magnet stacks made from identically shaped permanent magnets for magnetic resonance. Concepts Magn Reson Part A Bridg Educ Res 36(4):211-222. doi:10.1002/cmr.a.20165

UniProt: the Universal Protein Resource (2013) Bowman-Birk type proteinase inhibitor. http://www.uniprot.org/uniprot/P01055. Accessed 12 Mar 2013 (Archived by WebCite at http:// www.webcitation.org/6F3xoKJ7j)

Windt CW, Soltner H, Dusschoten DV, Blümler P (2011) A portable Halbach magnet that can be opened and closed without force: The NMR-CUFF. J Magn Reson 208(1):27-33. doi:10.1016/j.jmr.2010.09.020 